\title{
A case study of ECN data conversion for Korean and foreign ecological data integration
}

\author{
Hyeonjeong Lee ${ }^{1}$, Miyoung Shin ${ }^{* *}$ and Ohseok Kwon²
}

\begin{abstract}
In recent decades, as it becomes increasingly important to monitor and research long-term ecological changes, worldwide attempts are being conducted to integrate and manage ecological data in a unified framework. Especially domestic ecological data in South Korea should be first standardized based on predefined common protocols for data integration, since they are often scattered over many different systems in various forms. Additionally, foreign ecological data should be converted into a proper unified format to be used along with domestic data for association studies. In this study, our interest is to integrate ECN data with Korean domestic ecological data under our unified framework. For this purpose, we employed our semi-automatic data conversion tool to standardize foreign data and utilized ground beetle (Carabidae) datasets collected from 12 different observatory sites of ECN. We believe that our attempt to convert domestic and foreign ecological data into a standardized format in a systematic way will be quite useful for data integration and association analysis in many ecological and environmental studies.
\end{abstract}

Keywords: Ecological data, Ecological data conversion tool, Data standardization, Data integration

\section{Introduction}

In recent decades, it becomes increasingly significant to monitor and research long-term ecological changes (Michener and Jones 2012). Massive volume of ecological data are being collected according to predefined protocols throughout the world and demand new techniques for exploring hidden patterns at large spatial and temporal scales (Kelling et al. 2009). Some observatory networks, such as Long Term Ecological Research network (LTER) (San Gil et al. 2009) and the National Ecological Observatory Network (NEON) (Keller et al. 2008), have been providing platforms to access and share plenty of ecological data in the form of Ecological Metadata Language (EML) (Fegraus et al. 2005).

Despite these worldwide trends and attempts to integrate and manage long-term ecological data in a unified framework, domestic data in South Korea are still mostly scattered over many different systems in various forms, making it difficult for long-term ecological research. For

\footnotetext{
* Correspondence: shinmy@knu.ac.kr

${ }^{1}$ Bio-Intelligence \& Data Mining Laboratory, Graduate School of Electronics

Engineering, Kyungpook National University, Daegu 41566, Korea

Full list of author information is available at the end of the article
}

this reason, they should be first standardized in a common form for data integration and further analyses (Bonet et al. 2014). This need has led to the development of the Korean ecological data conversion tool (Lee et al. 2017) which converts raw data into common form based on some protocols. Moreover, foreign ecological data will be used along with domestic data for association studies if they could be converted into a proper unified format.

To find the feasibility of integration of foreign ecological data with Korean domestic data under our unified framework, we conducted foreign ecological data conversion with our tool and datasets of Environmental Change Network (ECN) (Morecroft et al. 2009). Brief process and result of ECN data conversion are described in the next sections.

\section{Materials and methods}

The protocols about ground beetles (Carabidae) selected by the long-term ecological research of Kyungpook National University in Korea were used as a predefined protocol (refer to Table 1). We utilized ground beetle (Carabidae) datasets collected from 12 different 
Table 1 Protocols of ground beetles (Carabidae) used in this study

\begin{tabular}{lll}
\hline Species (measurement) & Protocol & Attribute \\
\hline Ground beetles (Carabidae) & SC & $\begin{array}{l}\text { Start date, start time, search week, recorder, end date, end time, hour, maximum temperature, } \\
\text { minimum temperature, average temperature, humidity, wind speed, wind direction, weather, } \\
\text { reference, description }\end{array}$ \\
& Start date, trap ID, species, count, description \\
\hline
\end{tabular}

SC survey condition, SO species observed

observatory sites of ECN (Rennie et al. 2015). They contain two types of files: recording tables of species from each 12 sites and record date information table. Considering that domestic predefined protocol of Carabidae consists of two "species observed (SO)" and "survey condition (SC)," the form of ECN dataset is very similar to that of Korea. However, since foreign ecological data were collected according to their own protocols and therefore attributes (variables) or data types are generally different from ours, data conversion for standardization should be done before integrating foreign data with domestic data.
In ECN data conversion process, the first step is to upload ECN data file and select our predefined protocol. Input data is converted into common form based on chosen protocol which clarifies attributes and data types for target species, in our case, all species belonging to the ground beetles. Next, only some part of data which contain the target species are selectively extracted from input data. As the ECN data used in this conversion consists only of a number of ground beetle species corresponding to the protocol, no specific species selection is necessary at this step because all the input data should be used in the next conversion process. In the third step

Table 2 Data conversion results from 12 datasets of ECN. Numbers outside the parentheses indicate the total number of attributes defined in each data table, and the numbers inside the parentheses indicate how many attributes real records contain

\begin{tabular}{|c|c|c|c|c|c|c|c|c|}
\hline \multirow[t]{2}{*}{ Site } & \multirow[t]{2}{*}{ Dataset } & \multirow[t]{2}{*}{ Year(s) } & \multicolumn{2}{|l|}{ Before } & \multirow[t]{2}{*}{ Species } & \multirow[t]{2}{*}{ Protocol } & \multicolumn{2}{|l|}{ After } \\
\hline & & & Attributes & Records & & & Attributes & Records \\
\hline \multirow[t]{2}{*}{$\mathrm{ALI}$} & IG_date & 1994-2012 & $5(5)$ & 804 & Ground beetles (Carabidae) & SC & $16(3)$ & 804 \\
\hline & IG_record & 1994-2012 & $9(9)$ & 18,252 & & so & $5(5)$ & 18,252 \\
\hline \multirow[t]{2}{*}{ CAl } & IG_date & 1999-2012 & $5(5)$ & 601 & Ground beetles (Carabidae) & SC & $16(3)$ & 601 \\
\hline & IG_record & 1999-2012 & $9(9)$ & 6816 & & SO & $5(5)$ & 6816 \\
\hline \multirow[t]{2}{*}{ DRA } & IG_date & 1993-2009 & $5(5)$ & 631 & Ground beetles (Carabidae) & SC & $16(3)$ & 631 \\
\hline & IG_record & 1993-2009 & $9(9)$ & 9709 & & SO & $5(5)$ & 9709 \\
\hline \multirow[t]{2}{*}{ GLE } & IG_date & 1994-2012 & $5(5)$ & 879 & Ground beetles (Carabidae) & SC & $16(3)$ & 879 \\
\hline & IG_record & 1994-2012 & $9(9)$ & 10,320 & & SO & $5(5)$ & 10,320 \\
\hline \multirow[t]{2}{*}{ HIL } & IG_date & 1993-2012 & $5(5)$ & 402 & Ground beetles (Carabidae) & SC & $16(3)$ & 402 \\
\hline & IG_record & 1993-2012 & $9(9)$ & 12,836 & & SO & $5(5)$ & 12,836 \\
\hline \multirow[t]{2}{*}{ MOO } & IG_date & 1993-2012 & $5(5)$ & 1005 & Ground beetles (Carabidae) & SC & $16(3)$ & 1005 \\
\hline & IG_record & 1993-2012 & $9(9)$ & 7935 & & so & $5(5)$ & 7935 \\
\hline \multirow[t]{2}{*}{ NOR } & IG_date & 1993-2010 & $5(5)$ & 744 & Ground beetles (Carabidae) & SC & $16(3)$ & 744 \\
\hline & IG_record & 1993-2010 & $9(9)$ & 12,982 & & so & $5(5)$ & 12,982 \\
\hline \multirow[t]{2}{*}{ POR } & IG_date & 1994-2010 & $5(5)$ & 648 & Ground beetles (Carabidae) & SC & $16(3)$ & 648 \\
\hline & IG_record & 1994-2012 & $9(9)$ & 9322 & & so & $5(5)$ & 9322 \\
\hline \multirow[t]{2}{*}{ ROT } & IG_date & 1992-2009 & $5(5)$ & 523 & Ground beetles (Carabidae) & SC & $16(3)$ & 523 \\
\hline & IG_record & 1992-2009 & $9(9)$ & 18,188 & & SO & $5(5)$ & 18,188 \\
\hline \multirow[t]{2}{*}{ SNO } & IG_date & 1999-2012 & $5(5)$ & 660 & Ground beetles (Carabidae) & SC & $16(3)$ & 660 \\
\hline & IG_record & 1999-2012 & $9(9)$ & 10,748 & & SO & $5(5)$ & 10,748 \\
\hline \multirow[t]{2}{*}{ SOU } & IG_date & 1994-2012 & $5(5)$ & 806 & Ground beetles (Carabidae) & SC & $16(3)$ & 806 \\
\hline & IG_record & 1994-2012 & $9(9)$ & 11,377 & & SO & $5(5)$ & 11,377 \\
\hline \multirow[t]{2}{*}{ WYT } & IG_date & 1993-2012 & $5(5)$ & 840 & Ground beetles (Carabidae) & SC & $16(3)$ & 840 \\
\hline & IG_record & 1993-2012 & $9(9)$ & 11,754 & & SO & $5(5)$ & 11,754 \\
\hline
\end{tabular}


of attribute mapping, we specified the relations between ECN data attributes and standard attributes of the protocol by manually matching them with each other. Unlike the domestic protocol, the ECN data table does not contain some attributes related to the survey environment (temperature, humidity, wind, weather, etc.). Therefore, there is a little data to be converted under the survey environment attributes while the attributes for the species observation (search dates, species, and count) are all matched up and included in the following process. Finally, data type and unit of each attribute are properly transformed to suit the protocol. Attributes of "search start date" and "search end date" are standardized in the format of "YYYY-MM-DD" from "DD-MMYYYY" by using date conversion function, which adjusts the order of year, month, and day to fit the desired order of protocol. The substitution function converts all months written in English into numbers. For example, search date such as 01-MAR-2000 was changed to 200003-01 with date conversion and substitution functions. The standardized data is finally stored in a tabular csv file. The conversion results are summarized in Table 2.

\section{Results and discussion}

Using our semi-automatic data conversion tool, we could easily and efficiently standardized ECN datasets of ground beetles (Carabidae) which are different from our predefined protocol in various aspects such as data attributes and types. We expect that our attempt to convert domestic and foreign ecological data into a standardized format in a systematic way could provide broad usability for data integration and association analysis in many ecological and environmental studies.

\section{Abbreviations}

ECN: Environmental Change Network; EML: Ecological Metadata Language; LTER: Long Term Ecological Research network; NEON: National Ecological Observatory Network

\section{Acknowledgements}

We would like to appreciate anonymous reviewers for their valuable comments on the manuscript.

\section{Funding}

This subject is supported by Korea Ministry of Environment (MOE) as "Public Technology Program based on Environmental Policy (2014000210003)."

\section{Availability of data and materials}

Data are not publicly available to this article because they are used under license for the current study.

\section{Authors' contributions}

HL carried out the studies, performed the analysis, and wrote/reviewed the manuscript; MS participated in the design of the study and wrote/reviewed the manuscript; OK participated in the design of the study. All authors read and approved the final manuscript.

\section{Competing interests}

The authors declare that they have no competing interests.
Consent for publication

Not applicable.

Ethics approval and consent to participate

Not applicable.

\section{Publisher's Note}

Springer Nature remains neutral with regard to jurisdictional claims in published maps and institutional affiliations.

\section{Author details}

'Bio-Intelligence \& Data Mining Laboratory, Graduate School of Electronics Engineering, Kyungpook National University, Daegu 41566, Korea. ${ }^{2}$ School of Applied Bioscience, College of Agriculture and Life Sciences, Kyungpook National University, Daegu 41566, Korea.

Received: 23 April 2017 Accepted: 5 May 2017

Published online: 18 May 2017

\section{References}

Bonet, F. J., Pérez-Pérez, R., Benito, B. M., De Albuquerque, F. S., \& Zamora, R. (2014). Documenting, storing, and executing models in Ecology: a conceptual framework and real implementation in a global change monitoring program. Environmental Modelling \& Software, 52, 192-199.

Fegraus, E. H., Andelman, S., Jones, M. B., Schildhauer, M. (2005). Maximizing the value of ecological data with structured metadata: an introduction to Ecological Metadata Language (EML) and principles for metadata creation. Bulletin of the Ecological Society of America, 86, 158-168.

Keller, M., Schimel, D. S., Hargrove, W. W., Hoffman, F. M. (2008). A continental strategy for the National Ecological Observatory Network. The Ecological Society of America, 6, 282-284

Kelling, S., Hochachka, W. M., Fink, D., Riedewald, M., Caruana, R., Ballard, G., \& Hooker, G. (2009). Data-intensive science: a new paradig $m$ for biodiversity studies. BioScience, 59(7), 613-620.

Lee, H., Jung, H., Shin, M., \& Kwon, O. (2017). Developing a semi-automatic data conversion tool for Korean ecological data standardization. Journal of Ecology and Environment, 41, 11.

Michener, W. K., \& Jones, M. B. (2012). Ecoinformatics: supporting ecology as a data-intensive science. Trends in Ecology and Evolution, 27(2), 85-93.

Morecroft, M. D., et al. (2009). The UK Environmental Change Network: emerging trends in the composition of plant and animal communities and the physical environment. Biological Conservation, 142, 2814-2832.

Rennie, S., et al. (2015). UK Environmental Change Network (ECN) carabid beettle data: 1992-2012. https://doi.org/10.5285/4c9613ce-de52-41b1-9fde7c41f9199686.

San Gil, I., et al. (2009). The Long-Term Ecological Research community metadata standardisation project: a progress report. International Journal of Metadata, Semantics and Ontologies, 4, 141-153.
Submit your next manuscript to BioMed Central and we will help you at every step:

- We accept pre-submission inquiries

- Our selector tool helps you to find the most relevant journal

- We provide round the clock customer support

- Convenient online submission

- Thorough peer review

- Inclusion in PubMed and all major indexing services

- Maximum visibility for your research

Submit your manuscript at www.biomedcentral.com/submit
Biomed Central 